\title{
Identification of traffic accident risk-prone areas under low-light conditions
}

\author{
K. Ivan ${ }^{1}$, I. Haidu ${ }^{2}$, J. Benedek ${ }^{3}$, and S. M. Ciobanu ${ }^{1}$ \\ ${ }^{1}$ Babeş-Bolyai University of Cluj-Napoca, Faculty of Geography, Clinicilor Street, 5-7, 400006 Cluj-Napoca, Romania \\ ${ }^{2}$ Université de Lorraine, Laboratoire LOTERR - EA 7304, Île du Saulcy, 57045 Metz, France \\ ${ }^{3}$ University of Miskolc, Institute of World and Regional Economics, 3515 Miskolc, Hungary
}

Correspondence to: K. Ivan (ivan_kinga@yahoo.com)

Received: 22 January 2015 - Published in Nat. Hazards Earth Syst. Sci. Discuss.: 17 February 2015

Revised: 3 August 2015 - Accepted: 28 August 2015 - Published: 15 September 2015

\begin{abstract}
Besides other non-behavioural factors, low-light conditions significantly influence the frequency of traffic accidents in an urban environment. This paper intends to identify the impact of low-light conditions on traffic accidents in the city of Cluj-Napoca, Romania. The dependence degree between light and the number of traffic accidents was analysed using the Pearson correlation, and the relation between the spatial distribution of traffic accidents and the light conditions was determined by the frequency ratio model. The vulnerable areas within the city were identified based on the calculation of the injury rate for the $0.5 \mathrm{~km}^{2}$ areas uniformly distributed within the study area. The results show a strong linear correlation between the low-light conditions and the number of traffic accidents in terms of three seasonal variations and a high probability of traffic accident occurrence under the above-mentioned conditions at the city entrances/exits, which represent vulnerable areas within the study area. Knowing the linear dependence and the spatial relation between the low light and the number of traffic accidents, as well as the consequences induced by their occurrence, enabled us to identify the areas of high traffic accident risk in Cluj-Napoca.
\end{abstract}

\section{Introduction}

Road traffic safety deals with a complexity of problems, as there are some factors that contribute to its disturbance: drivers' behaviour in traffic, deterioration of infrastructure, weather conditions, light conditions and intensification of traffic. Due to the continuous increase of traffic, the number of accidents increases significantly while road traffic safety becomes more difficult to control.

Cluj-Napoca, Romania, is the most important urban centre in Transylvania, with almost half a million inhabitants during the academic year. These arterial thoroughfares are congested mainly in the east-west direction, representing connection axes with the cities of Baia Mare, Oradea, Zalău and Turda (Fig. 1), with an average daily traffic of 84390 vehicles. The intense road traffic in the city of Cluj-Napoca is due to the transit traffic, its area of economic influence and the large number of cars registered in the city and county. According to the data published by the National Institute of Statistics, 165619 vehicles were registered in Cluj County in 2012. The traffic accidents in the city of Cluj-Napoca have a generally high frequency along the main arterial roads.

In order to mitigate the road accidents in the city, the triggering factors need to be identified first. In Cluj-Napoca, winter ends only in March, when the snow and ice layer disappears from the roads. The light duration increases each month. After the summer solstice, the duration of natural light starts to decrease. At the same time, in July-August the amount of precipitation reaches a minimum and then, from one month to another, successively increases until November. The rainfalls have a frontal character; the humidity also increases, while in autumn, fog occurs. After November, the precipitation in Cluj-Napoca changes into solid precipitation, and the authorities do not always manage to completely clean the roads of the icy snow layer. The slippery roads, combined with the low visibility, determine the occurrence of a new statistical relationship $(y=0.01 x+2.9)$ which is specific to the December-February period. The authors called this relation- 


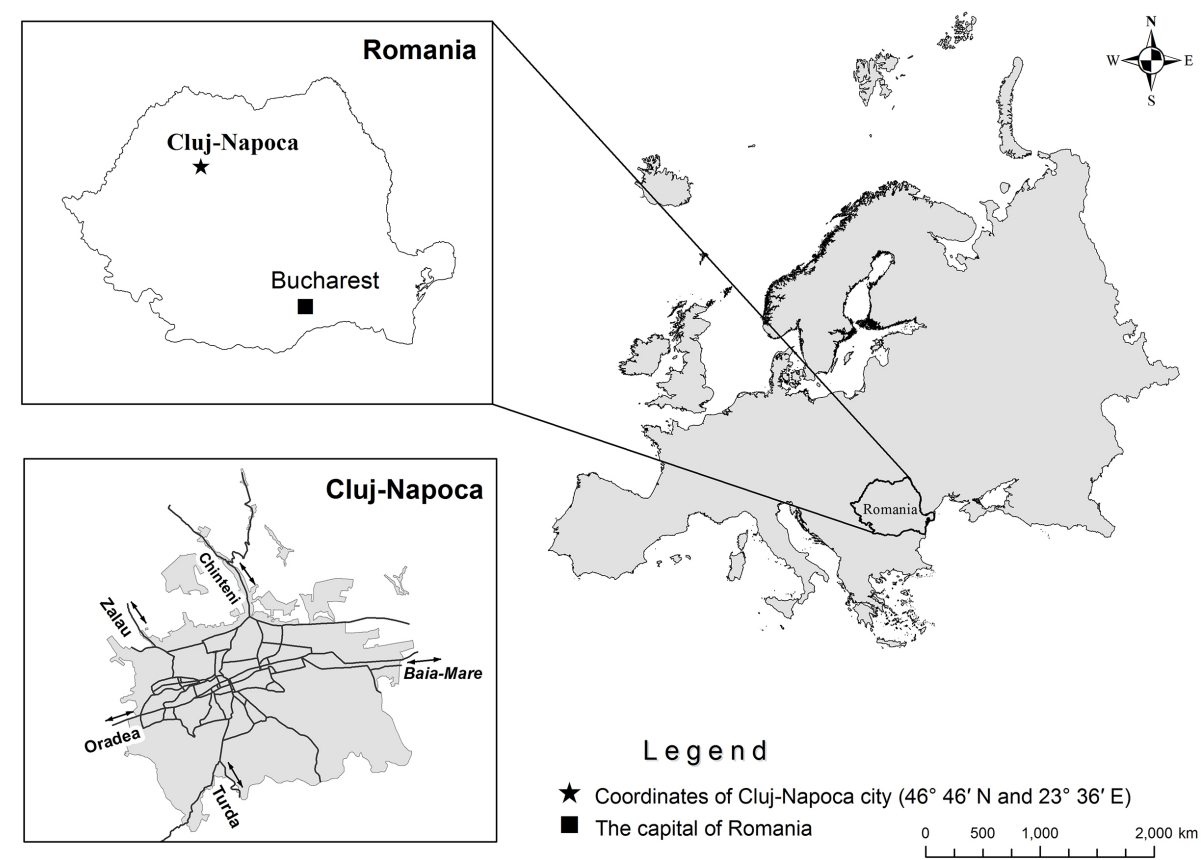

Figure 1. Location of Cluj-Napoca.

ship the "snowy and icy" type of relationship to distinguish it from the other two statistical relationships (Fig. 4).

Road traffic accidents are the result of both behavioural and non-behavioural factors. The relation between accident frequency and the non-behavioural factors influencing accident occurrence has been investigated in many studies. Previous research proved that non-behavioural factors have a significant influence on the occurrence of traffic accidents (Chang, 2005; Garber and Wu, 2001; Lee and Mannering, 1999; Petrova, 2011; Zou et al., 2012). These focused especially on geometrical road characteristics, traffic characteristics and climatic conditions. The loss of life caused by bad weather conditions along the road network was analysed by Petrucci and Pasqua (2012). Chang (2005) proved that the number of traffic lanes, the average daily traffic and the length of the road section have a significant influence on accident occurrence.

Within this paper we aimed to assess the traffic accident occurrence risk under low-light conditions. The research is focused exclusively on the analysis of the relation between road traffic accidents and light conditions, which are considered to be non-behavioural factors in road traffic accidents. The road traffic accidents in urban areas may occur under various light conditions: dawn, daylight, cloudy sky, sunset or street light. The degree of dependence between the traffic accidents and the light conditions is analysed in this paper by means of Pearson's statistical correlation coefficient. The research conducted by Al-Harbi et al. (2012) by means of the Pearson correlation coefficient investigated the relation between meteorological conditions and traffic accidents, and the results highlighted a strong correlation between temperature and accidents during spring, autumn and winter. Pearson's correlation coefficient was also used to analyse the relation between traffic accidents and environmental physical activity parameters in the study conducted by Stoupel et al. (2009).

In the present paper, researching the connection between traffic accidents and low-light conditions enables us to determine the hazard, i.e. the triggering phenomenon. Hazards may be natural (earthquake, snow, cold wave, heavy rainfalls, low light, etc.) or man-made (industrial, technological, chemical, etc.). The natural-hazard fatality risk caused by avalanches on road networks was analysed by Zischg et al. (2005). The current research focuses on the analysis of the natural hazard of light as a triggering phenomenon for the occurrence of traffic accidents.

In studying the relation between the spatial distribution of accidents and the various light conditions, a frequency ratio model and quadrat analysis were used. We decided to use quadrat analysis because this enabled us to identify the $0.5 \mathrm{~km}^{2}$ accident-prone areas in the city of Cluj-Napoca. Quadrat analysis was used for the study of spatial relations among traffic accidents by Mulrooney and Green (2012) and for the identification of areas with a high rate of crime by Wing and Tynon (2006). A frequency ratio model was used by Lee and Pradhan (2007) when analysing the landslide susceptibility of slopes. We have adapted this method in our study to determine the areas prone to road traffic incidents in the city concomitantly with the decrease of light conditions. Susceptibility represents the occurrence potential of a 
traffic accident in a certain location, in our case the $0.5 \mathrm{~km}^{2}$ areas.

Vulnerability represents the consequences resulting from the occurrence of traffic accidents, as these have a significant impact on the community. They may have a long-term occurrence (the basic vulnerability) or a short-term occurrence (the acute vulnerability) of an extreme nature (Benedek, 2002). Vulnerability may be direct (material or moral losses) or indirect: economic (disruption of shops and factories supply), social (access to universities, schools) and security related (access of police, fire fighters, ambulance). Direct vulnerability refers to the damages resulting immediately after the occurrence of the event and is closely connected to the material or moral losses induced by a traffic accident. The moral losses refer to the number of injured persons and deaths caused by the accident, while the material losses refer to the value of the damaged goods. In this paper we take into consideration all the accidents regardless of whether such events led to loss of life or only to injuries. Indirect vulnerability refers to the distant consequences of the event and is closely connected to the significance of the event, the accessibility degree and connectivity of the road network. In the present study we analysed only the direct vulnerability, i.e. the injury rate resulting from the traffic accidents.

In this paper, the risk is addressed as a result of a combination of hazard, susceptibility and vulnerability. Some authors assess the risk as a product of probability and consequences (Stodola, 2008; Ferrier and Haque, 2003). After analysing the three components - hazard, susceptibility and vulnerability - the present research determines the risk of traffic accidents occurrence under low-light conditions. The purpose of this paper is to influence public authorities to introduce artificial light earlier, to more rapidly clean the roads of snow and, last but not least, to restrict alcohol consumption of drivers. The first part of the paper describes the database used for risk assessment, while the second part presents an assessment of the traffic accident risk under low-light conditions as the sum of the three components.

\section{Data description}

In order to assess the risk of traffic accident occurrence under low-light conditions, some data regarding the number of traffic accidents and the light conditions at their occurrence are necessary. A total number of 663 traffic accidents were recorded in Cluj-Napoca during the January 2010-December 2014 period. The data regarding the traffic accidents were obtained from the Cluj County police inspectorate and the local press. The data contain information regarding the time, place, time of day and week, light conditions and number of victims of traffic accidents over the entire period of the study. The data on the road network contain information referring to the average speed of vehicles and the mean value of the accidents for each road segment in the city.
The data regarding the number of low visibility hours were calculated using the following steps: monthly darkness hours specific to the geographical coordinates of Cluj-Napoca were added to the number of hours with hard clouds and to the number of hours with hard fog, subtracting the number of hours of strong street light for each month. All these parameters were appreciated on the base of the ratio between two terms: the normal traffic visibility and the low visibility as defined by traffic rules. Thus, the values used for regression analysis were defined in this paper as being the real low visibility hours. We note that we have worked with the averaged values for each month.

\section{Risk assessment}

In the present paper, the risk is assessed as a sum of information resulting from hazard, susceptibility and vulnerability analysis. Risk as a sum of hazard, susceptibility and vulnerability was studied before by Panizza (1994), cited by Trizna (2000) and Carrega $(2003,2008)$. Therefore, the risk assessment in this study implies the determination of the dependence degree and of the spatial relation between the traffic accidents and the low-light conditions (hazard and susceptibility) as well as of the consequences induced by their occurrence (vulnerability).

\subsection{Hazard analysis}

In this paper, hazard is identified by researching the relation between traffic accidents and the number of low visibility hours based on the statistical correlation.

To set up a dependence relation, the two variables were distributed in a system of $X O Y$ axes, thus forming a correlation group. The correlation between the two variables, the low light and the traffic accidents, is reflected by the simple linear regression model as follows:

$Y=a X+b$,

where $X$ is the cause (real low traffic visibility) and $Y$ is the effect (road traffic accidents).

The statistical analysis identified three clusters, each with a certain tendency within the distribution, and these corresponded to three seasonal variations: end of summerautumn, spring-beginning of summer and winter. The dependence between the two variables corresponding to the three seasonal variations was graphically represented by three regression lines which describe the relationship between the $\mathrm{Y}$ and $\mathrm{X}$ variables.

The intensity of the linear dependence between these two variables for each particular tendency was determined by means of the Pearson correlation coefficient $(r)$. The Pearson correlation coefficient of two variables, $x_{i}$ and $y_{i}$, was 
calculated by the following formula (Lee and Wong, 2001):

$r=\frac{\frac{\sum_{i=1}^{n} x_{i} y_{i}}{n}-\bar{X} \cdot \bar{Y}}{S_{x} S_{y}}$,

where $\bar{X}$ and $\bar{Y}$ represent the average of $x$ and $y$, and $S_{x}$ and $S_{y}$ represent the standard deviation of $x$ and $y$, calculated by the following formulas (Lee and Wong, 2001):

$S_{x}=\sqrt{\frac{\sum_{n=1}^{n} x^{2}}{n}}-\bar{X}^{2}$,

$S_{y}=\sqrt{\frac{\sum_{n=1}^{n} y^{2}}{n}}-\bar{Y}^{2}$.

\subsection{Susceptibility analysis}

The identification of susceptible areas involved analysing the relation between the spatial distribution of the accidents on a $0.5 \mathrm{~km}^{2}$ area and the various light conditions (dawn, daylight, cloudy sky, sunset or street light).

The spatial distribution of the accidents in equal and homogenous areas was performed by means of the quadrat analysis. The quadrat analysis was conducted in Arc View 3.2 by means of a script developed by Lee and Wong (2001). This analysis involved covering the study area with a grid of hexagons of equal size and the identification of the number of accidents placed in each hexagon. We opted for the hexagon due to a better visual display compared to the traditional rectangular network; the representation by hexagon offers a higher accuracy (Carr et al., 1992). The size of a chosen hexagon was $0.5 \mathrm{~km}^{2}$, which allowed us to determine the areas susceptible to traffic accidents by relating the analysis to equal plots in the study area.

The determination procedure for susceptible areas consisted of calculating the ratio of the traffic accidents in each $0.5 \mathrm{~km}^{2}$ area for each light condition to the percentage of the total number of accidents in the $0.5 \mathrm{~km}^{2}$ area. Thus, to determine the areas susceptible to the occurrence of traffic accidents, their frequency ratio was calculated for five different light conditions: dawn, daylight, cloudy sky, sunset or street light.

The susceptibility index of accident occurrence under lowlight conditions was calculated by summing up the accidentfrequency ratio for each condition and assignment of weights directly proportional with the decrease of the light conditions. Thus, the light conditions were assigned a weight of $35 \%$ during the night $(N), 5 \%$ during the day $(D), 25 \%$ at sunset $(S), 20 \%$ at dawn $(D w)$ and $15 \%$ under cloudy sky conditions $(C)$. The formula used in calculating the susceptibility index is the following (adapted and modified from Lee and Pradhan, 2007):

$S=\frac{35 \times N+5 \times D+25 \times S+20 \times D w+15 \times C}{100}$, where $S$ is the susceptibility index, $N$ is the frequency ratio of accidents occurring at night, $D$ is the frequency ratio of accidents occurring during the day, $S$ is the frequency ratio of accidents occurring at sunset, $D w$ is the frequency ratio of accidents occurring at dawn and $C$ is the frequency ratio of accidents occurring under cloudy sky conditions.

The locations of high susceptibility rates represent the entrances/exits of the city: in the northern part along the axis of Oasului Street, in the eastern part along Muncii Boulevard, in the southern part along Calea Turzii Street and in the western part of the Calea Floreşti-1 Decembrie 1918 Boulevard route (Fig. 2).

These axes of entrances/exits of the city, according to the study conducted by Ivan and Haidu (2012), correspond to the main arterial roads with intense traffic and a high number of victims.

\subsection{Vulnerability analysis}

This research comprises only the direct vulnerability, i.e. the direct consequences induced as a result of the traffic accidents, and the moral losses (victims of traffic accidents). In the present study, the moral loss includes both the number of deaths and the number of injured persons; we did not have separate access to the number of deaths, so we included all injured people.

The vulnerability analysis was conducted by calculating the injury rate as a ratio of the number of victims to the total number of accidents that occurred during the study period for each $0.5 \mathrm{~km}^{2}$ area in the city. The injury rate was calculated by the following formula (Pirotti et al., 2010), taking the human factor into consideration:

$\mathrm{IR}=\left(\frac{I}{A}\right) \times 100$,

where IR is injury rate, $I$ is the number of injured persons and $A$ is the number of accidents.

High vulnerability rates were recorded at the entrances/exits of the city, including those connecting to the north to Chinteni, to the east to Baia Mare and to the south to the town of Turda (Fig. 3). Lower vulnerability rates were recorded in the downtown area of the city.

\section{Results and discussions}

The areas with different degrees of accident occurrence risk under low-light conditions were determined in this paper by summing up the information obtained as a result of hazard, susceptibility and vulnerability analysis.

The research conducted on the statistical relation between the variables of traffic accidents and low light in order to identify the hazard revealed a linear dependence between them for each separate cluster identified. The correlation graph (Fig. 4) illustrates that the average number of accidents 


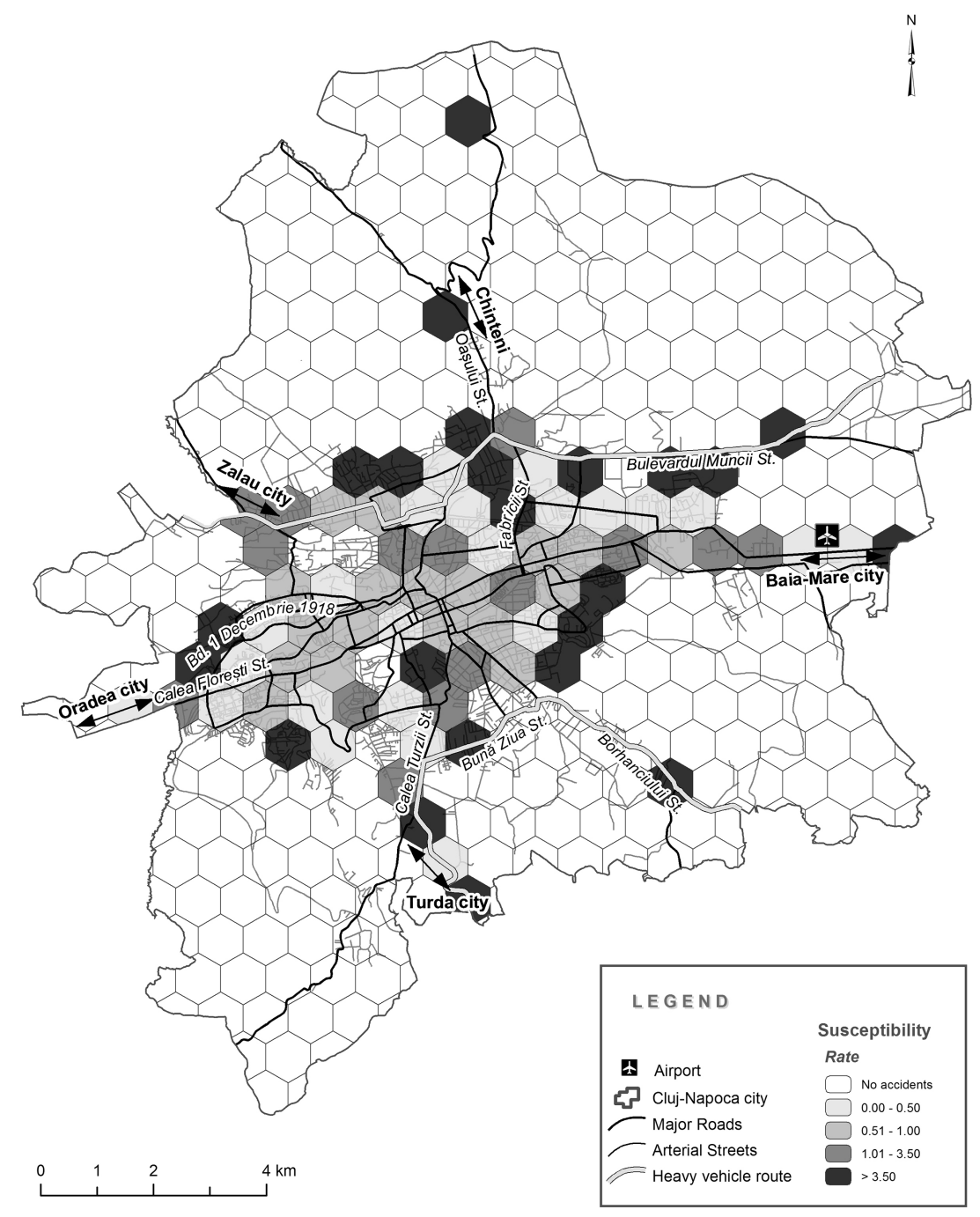

Figure 2. The map of areas susceptible to traffic accidents under low-light conditions in Cluj-Napoca (2010-2014).

$\left(y_{i}\right)$ increases concomitantly with the average number of real low traffic visibility hours $\left(x_{i}\right)$. There is a direct linear connection between the two variables $(X$ and $Y$ ).

The intensity of linear dependence between the two variables corresponding to the three seasonal variations is given by the correlation coefficients, which are positive for each of the variations. The Pearson correlation coefficient with the highest value is 0.97 and corresponds to the months of March, April, May and June, while 0.91 corresponds to the months of December, January and February and 0.85 to the months of July, August, September, October and November. Artificial light is added suddenly in December to the natural illumination, which is in constant reduction from one month to another. Therefore, a threshold appears in terms of continuity of the real light (as the sum of the natural light and artificial light), which can influence the number of accidents. On the $O X$ axis in Fig. 4 we have real hours of monthly low visibility, which includes the average number of hours with clouds and fog.

The cloud of points in Fig. 4 is split into three interesting seasons, because November is more similar to October and previous months than to December. Usually in December, January and February in Cluj there is snow, which is partially cleaned by authorities, while in the previous season the quantity of rainfall increases successively from July until November. After that, the rainfall changes in solid precipitation. Figure 4 does not show a simple linear relationship for the data ensemble, but it does clearly show that there are three seasonal clusters. In each cluster, the relationship is linear, but the fact that the value pairs "low-light condition" and "number of accidents" describe independent clusters shows the lack of a simple correlation.

This dependence between the two variables is represented on the correlation graph by three regression lines, and the best approximation of all these is ensured by the regression 


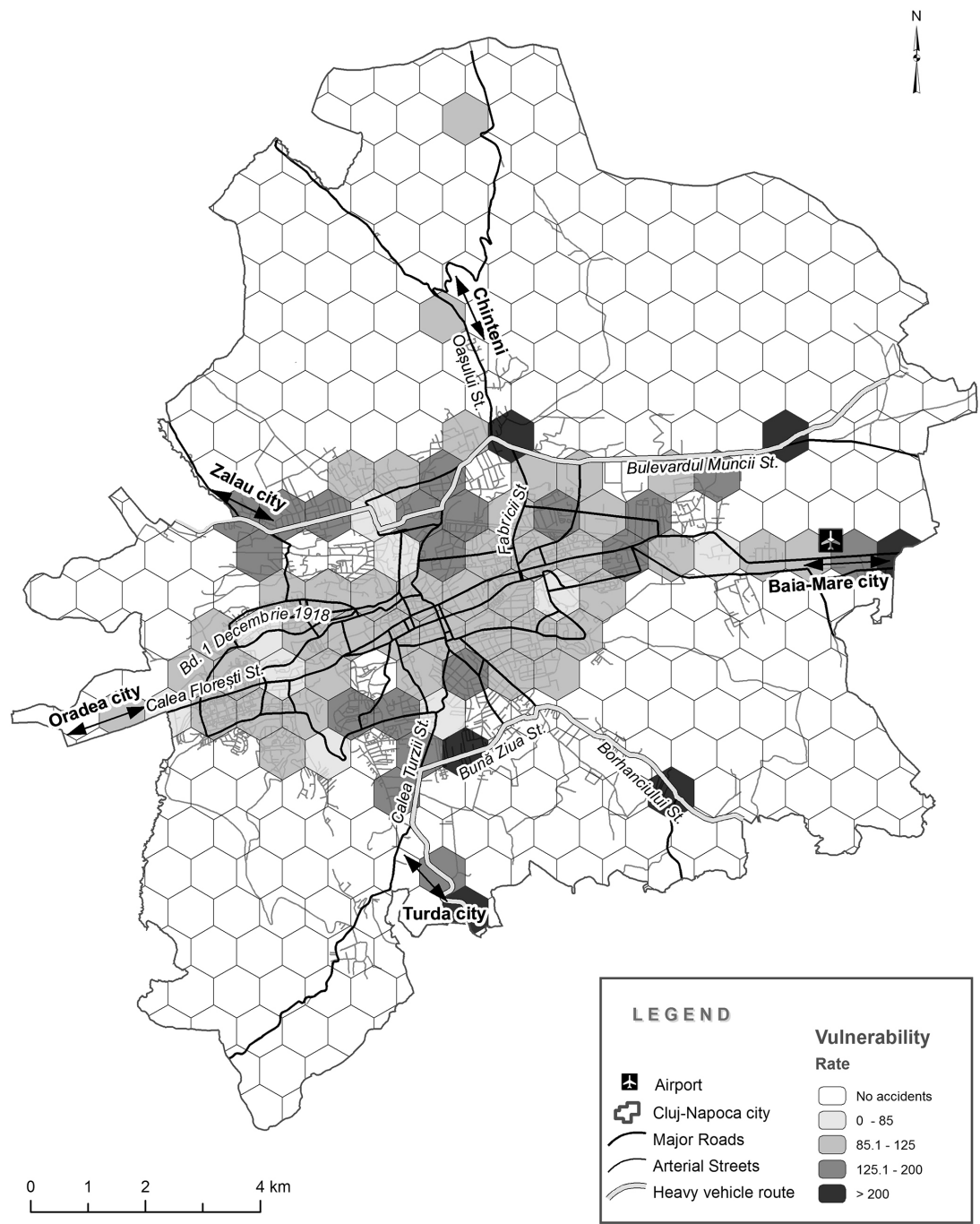

Figure 3. The map of vulnerable areas in the city of Cluj-Napoca (2010-2014).

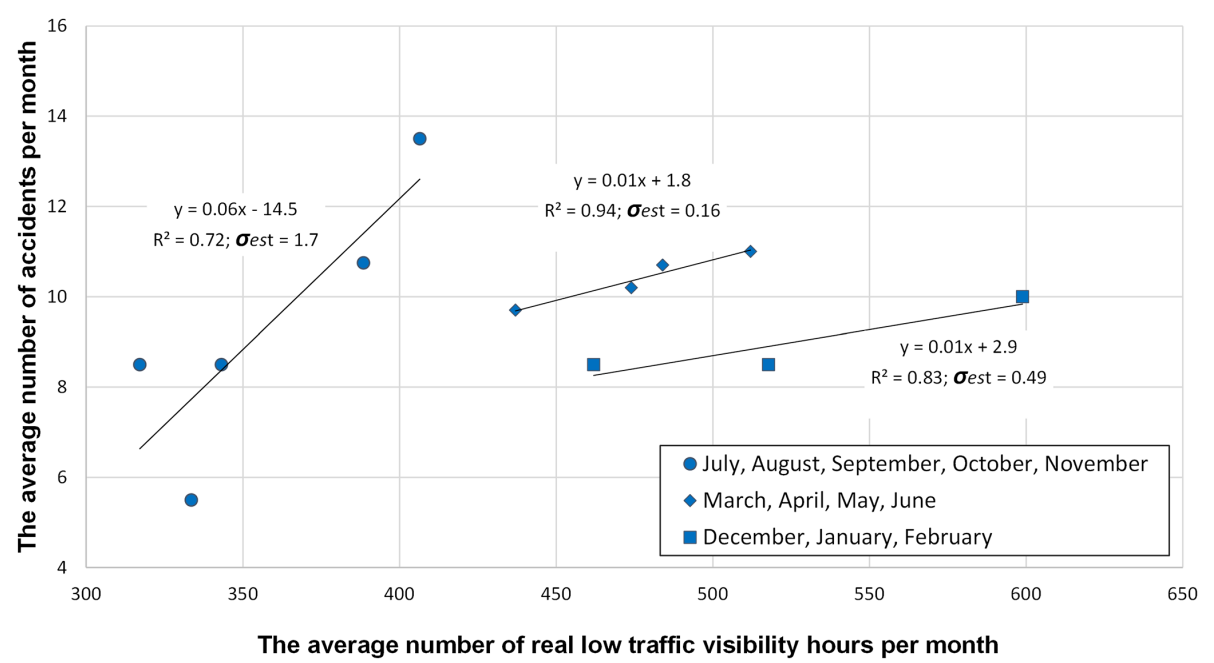

Figure 4. The regression lines corresponding to the three seasonal variations (2010-2014). 


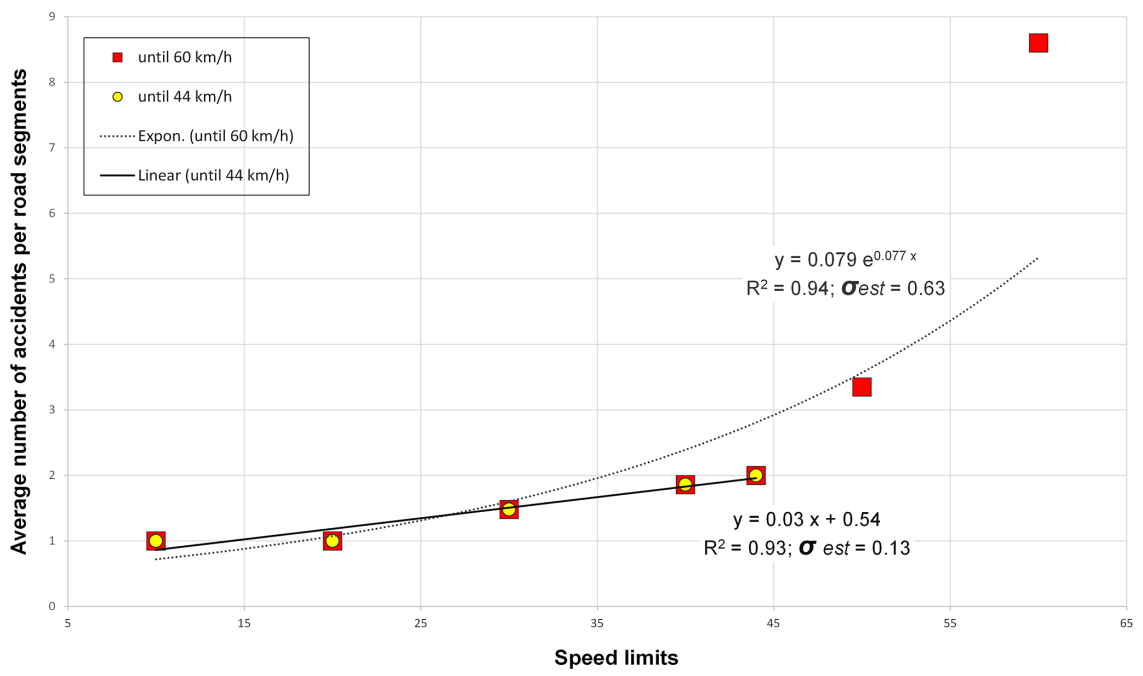

Figure 5. Graph correlating speed and traffic accidents (2010-2014).

line with a determination coefficient of 0.94 . The $0.72,0.94$ and 0.83 determination coefficients are close to 1 and indicate the fact that low light $(X)$ explains the variation of the $Y$ variable (traffic accidents) in the ratio of 72,94 and $83 \%$, which shows that the model is valid in explaining the variation of the road traffic accidents.

The identification of the areas susceptible to traffic accidents produced under low-light conditions emphasises their high rate at the city outskirts, particularly at the entrance/exit points of the city where the speed of vehicles is high.

The research of the dependence degree between the average of traffic accidents $(Y)$ and the average vehicle speed $(X)$ at the level of each road segment for the study period highlighted a direct statistical relation. This illustrates the fact that an increase of $y_{i}$ corresponds to an increase of $x_{i}$.

The statistical analysis has identified two clusters within the distribution: one corresponding to the average speeds up to $44 \mathrm{~km} \mathrm{~h}^{-1}$ and the other one including the speeds of $50 \mathrm{~km} \mathrm{~h}^{-1}$ to $60 \mathrm{~km} \mathrm{~h}^{-1}$ and probably higher. Speeds higher than $60 \mathrm{~km} \mathrm{~h}^{-1}$ were not analysed in this study. The intensity of the linear dependence between the two variables was determined by means of the statistical correlation. The values of Pearson's correlation coefficient obtained within this analysis are high: 0.96 in case of the dependence between the traffic accidents and the speed of vehicles up to $44 \mathrm{~km} \mathrm{~h}^{-1}$. The Pearson correlation coefficient between the traffic accidents and the vehicle speeds up to $60 \mathrm{~km} \mathrm{~h}^{-1}$ was a little lower than 0.78 . The dependence between the variables, traffic accidents and speeds up to $60 \mathrm{~km} \mathrm{~h}^{-1}$ was graphically represented by means of an exponential curve, while that between the traffic accidents and the speeds up to $44 \mathrm{~km} \mathrm{~h}^{-1}$ was represented by means of a linear curve (Fig. 5). The 0.94 and 0.93 determination coefficients indicate the fact that speed of vehicles $(X)$ explains the variation of the $Y$ variable (traffic accidents) in the ratio of 94 and $93 \%$, which shows that the model is valid in explaining the variation of the road traffic accidents.

These results explain that, in Cluj-Napoca, speed is another factor in the occurrence of traffic accidents besides low light and intense road traffic.

After identifying the vulnerable areas, the results have shown low rates in the central areas of the city, where accident frequency was high during the period of study. This highlights the fact that the severity of road accidents was low in this area although the frequency of the accidents was high. The high accident frequency in these areas is due to the intense road traffic, as it comprises the main traffic roads in the city that host the transit traffic. This is due to the architecture of the city, which extends on the east-west axis, as well as to the traffic infrastructure which could not adapt to the increase of the road traffic density in the city.

The results of the risk assessment emphasized a high degree of traffic accident occurrence under low-light conditions in the areas with a high vulnerability rate; this explains the fact that the degree of risk depends on the population's degree of vulnerability.

The areas with a high rate of traffic accidents under lowlight conditions are illustrated on the map in dark grey and are located approximately at the entrances/exits of the city. Hence, we find six such areas: three of them located in the south of the city, one in the north and two in the east (Fig. 6).

The most southern high-risk area includes the southern end of Calea Turzii Street, representing the entrance/exit of ClujNapoca towards the town of Turda. Here the high risk is explained by the fact that visibility is disturbed by the presence of two dangerous curves in conjunction with high vehicle speed on this arterial road $\left(50 \mathrm{~km} \mathrm{~h}^{-1}\right)$ with the intense vehicle flow (the average daily traffic is 476 vehicles). The second southern area with a high risk of road traffic accidents under low-light conditions includes the streets Bună Ziua and 


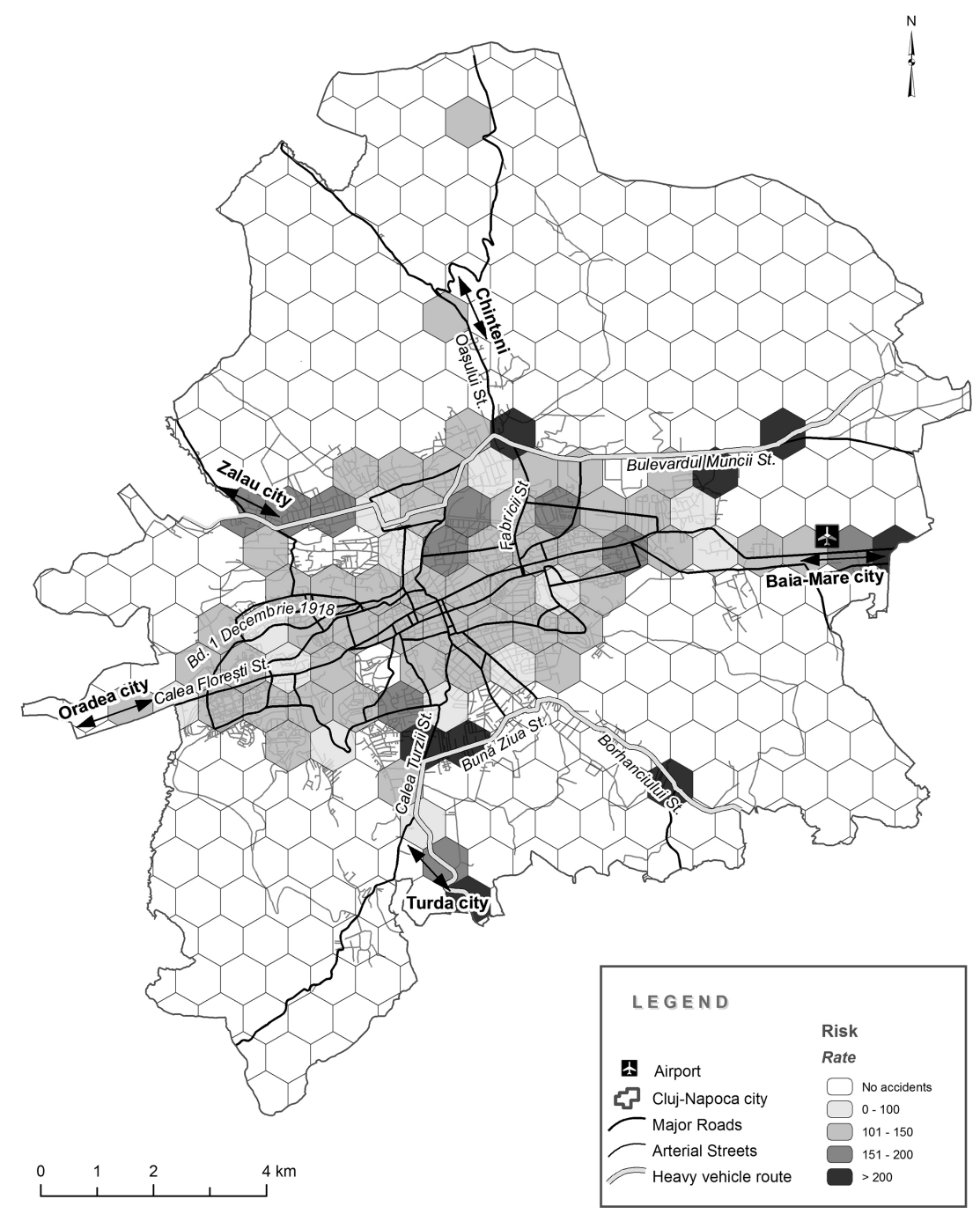

Figure 6. The map of traffic accident occurrence risk areas under low-light conditions in Cluj-Napoca (2010-2014).

Borhanci, where access by heavy vehicles is allowed only with authorisation. In this area, the number of heavy vehicles per day is on average 179 .

In the northern part of the city, the high-risk areas include the following arterial streets: Oasului Street, Fabricii Street and Muncii Boulevard. The high risk in this area is due to the intense road traffic, the presence of heavy vehicles and the high speed along certain sectors. The average daily traffic on Oasului Street is 977 vehicles, the average speed of vehicles is $60 \mathrm{~km} \mathrm{~h}^{-1}$ and the number of heavy vehicles per day is more than 42 . The average daily traffic on the Fabricii Street is 163 vehicles, the average vehicle speed is $50 \mathrm{~km} \mathrm{~h}^{-1}$ and the number of heavy vehicles per day is 161 .

In the eastern part of Cluj-Napoca are two high-risk areas in terms of traffic accidents under low-light conditions: one is located in the airport area and the other at the end of Muncii Boulevard. The high-risk rate in these areas is due to the intense traffic (the average daily traffic is 103 vehicles) and to the high vehicle speed near the airport $\left(50 \mathrm{~km} \mathrm{~h}^{-1}\right.$ average speed).

\section{Conclusions}

The assessment of traffic accident occurrence risk under lowlight conditions was determined as a sum of hazard, susceptibility and vulnerability. The areas with the highest risk rates identified at the city level include the most important arterial roads, consisting generally of entrances/exits of the city such as Calea Turzii, Oasului Street, Muncii Boulevard and the airport area. These arterial roads represent important transit axes, with high speed of vehicles and intense traffic. The high vehicle speed on Calea Turzii Street is $50 \mathrm{~km} \mathrm{~h}^{-1}$ and the average daily traffic is 476 vehicles; on Oasului Street the average speed of vehicles is $60 \mathrm{~km} \mathrm{~h}^{-1}$ and the average daily traffic is 977 vehicles; on Muncii Boulevard and the airport 
area, the average daily traffic is 103 vehicles and the average speed of vehicles is $50 \mathrm{~km} \mathrm{~h}^{-1}$.

The regression analysis shows that, together with the real low traffic visibility, the combination of weather conditions is very important to the occurrence of traffic accidents. By combining the two determining factors, we can explain why there is no simple regression but rather three interesting seasons of traffic risk that do not have a close connection with the climatic seasons.

During March-June, the hours of real low traffic visibility decrease continuously, parallel to the increases of average temperature and the convective processes. As a result, the nature of spring and early summer rainfalls is irregular, with predominantly storms and torrential rainfalls. The corresponding statistical cluster in Fig. 4 could be explained by the traffic conditions dominated by the torrential rainfall. During July-November, the number of hours of real traffic visibility has a descending trend, while the amount of liquid precipitation and the humidity successively increase until November. The traffic conditions become worse and worse, being dominated by the rise in humidity. These weather conditions justify the existence of the statistic cluster composed of specific data for the period July-November. The third statistic cluster corresponds to the season of solid precipitation, which, together with fog and long-lasting nights, increasingly worsens the traffic conditions. December-January-February is the worst traffic season due to the low luminosity, which causes dangerous streets.

Research on the degree of dependence between road traffic accidents and non-behavioural factors (speed and low light) emphasized the fact that light and speed are main factors in accidents. The knowledge of these factors and the identification of risk areas may help local authorities in creating and implementing measures for the prevention and mitigation of road traffic accidents. These measures should include the expansion and development of street light, lowering the speed limits on certain traffic routes, increasing the placement of warning signboards, etc. If implemented, all these measures would lead to increased road safety.

Acknowledgements. This paper is a result of doctoral research made possible by the financial support of the Sectoral Operational Programme for Human Resources Development 2007-2013, co-financed by the European Social Fund under the project POSDRU/159/1.5/S/132400 - "Young successful researchers professional development in an international and interdisciplinary environment".

Edited by: R. Lasaponara

Reviewed by: A. De Santis and K. Németh

\section{References}

Al-Harbi, M., Yassin, M. F., and Bin Shams, M.: Stochastic modeling of the impact of meteorological conditions on road traffic accidents, Stoch. Env. Res. Risk A., 26, 739-750, 2012.

Benedek, J.: Human Risks, Riscuri si Catastrofe, Cluj University Press, Cluj-Napoca, 1, 43-54, 2002.

Carr, D. B., Olsen, A. R., and White, D.: Hexagon mosaic maps for display of univariate and bivariate geographical data, Cartogr. Geogr. Inform., 19, 228-236, 1992.

Carrega, P.: The Natural Risks Connected to Rainfall and Drought: Drawing Maps of Extreme Rainfalls and Risks of Forest Fires within a Mediterranean Region: Toscana (Italy), Riscuri si Catastrofe, Cluj University Press, Cluj-Napoca, 2, 271-286, 2003.

Carrega, P.: Forest fire risk in region mediterranean: understanding and development, Actes du XXIIe colloque de l'Association Internationale de Climatologie, HAL, Montpellier, 11-23, 2008.

Chang, L.-Y.: Analysis of freeway accident frequencies: Negative binomial regression versus artificial neural network, Safety Sci., 43, 541-557, 2005.

Ferrier, N. and Haque, E. C.: Hazards Risk Assessment Methodology for Emergency Managers: A Standardized Framework for Application, Nat. Hazards, 28, 271-290, 2003.

Garber, N. J. and Wu, L.: Stochastic models relating crash probabilities with geometric and corresponding traffic characteristics data, Publication UVACTS-5-15-74, Center for Transportation Studies, University of Virginia, Charlottesville, VA, 2001.

Ivan, K. and Haidu, I.: The spatio-temporal distribution of road accidents in Cluj-Napoca, Geographia Technica, 16, 32-38, 2012.

Lee, J. and Mannering, F.: Analysis of roadside accident frequency and severity and roadside safety management, Washington State Department of Transportation, University of Washington, Seattle, USA, 1999.

Lee, J. and Wong, D. W. S.: Statistical Analysis with ArcView GIS, John Wiley and Sons, New York, 192 pp., 2001.

Lee, S. and Pradhan, B.: Landslide hazard mapping at Selangor, Malaysia using frequency ratio and logistic models, Landslides, 4, 33-41, 2007.

Mulrooney, T. and Green, E.: Exploring Patterns And Factors Related To Deer-Vehicle Collisions In Central North Carolina, Southeastern Division of the Association of American Geographers, Annual Meeting, Asheville, North Carolina, 18-20 November, 2012.

National Institute of Statistics, Romania: www.insse.ro., last access: August 2012.

Petrova, E. G.: Natural factors of technological accidents: the case of Russia, Nat. Hazards Earth Syst. Sci., 11, 2227-2234, doi:10.5194/nhess-11-2227-2011, 2011.

Petrucci, O. and Pasqua, A. A.: Damaging events along roads during bad weather periods: a case study in Calabria (Italy), Nat. Hazards Earth Syst. Sci., 12, 365-378, doi:10.5194/nhess-12-3652012, 2012.

Pirotti, F., Guarnieri, A., and Vettore, A.: Road safety analysis using web-based collaborative GIS, vol. 34, The International Archives of the Photogrammetry, Remote Sensing and Spatial Information Sciences, Como, Italy, 2010. 
Stodola, J.: Possibilities of traffic accidents and risk crash evaluation, R\&RATA \# 2, 1, 134-138, 2008.

Stoupel, E., Babayev, E. S., Shustarev, P. N., Abramson, E., Israelevich, P., and Sulkes, J.: Traffic accidents and environmental physical activity, Int. J. Biometeorol., 53, 523-534, 2009.

Trizna, M.: Flood threat in an area - topical natural hazard, Acta Universitatis Palackianae Olomucensis, Geographica, 36, 89-96, 2000.

Wing, M. G. and Tynon, J.: Crime mapping and spatial analysis in National Forests, J. Forest., 104, 293-298, 2006.
Zischg, A., Fuchs, S., Keiler, M., and Stötter, J.: Temporal variability of damage potential on roads as a conceptual contribution towards a short-term avalanche risk simulation, Nat. Hazards Earth Syst. Sci., 5, 235-242, doi:10.5194/nhess-5-235-2005, 2005.

Zou, Y., Lord, D., Zhang, Y., and Peng, Y.: Comparison of Sichel and Negative Binomial Models in Estimating Empirical Bayes Estimate, in: Transportation Research Record: Journal of the Transportation Research Board, No. 2392, Transportation Research Board of the National Academies, Washington, D. C., 11$21,2013$. 